\title{
Characterization of the Demographics and Psychiatric Co-Morbidites Among Clients of a Human Rights Clinic in Miami-Dade County, Florida, United States
}

Samuel Kareff ${ }^{1}$, Chanelle Diaz ${ }^{2}$, Amy Zeigler ${ }^{3}$, J. Grey Faulkenberry ${ }^{4}$, Brigitte F. Utter ${ }^{5}$, Cecily M. Barber ${ }^{6}$, Stephen Symes ${ }^{7}$

1. Internal Medicine, MedStar Georgetown University Hospital, Washington, D.C., USA 2. Internal Medicine, Montefiore Medical Center, New York, USA 3. Emergency Medicine, University of Pittsburgh, Pittsburgh, USA 4. Biomedical and Health Informatics, Children's Hospital of Philadelphia, Philadelphia, USA 5. Family Medicine, Denver Health and Hospitals, Denver, USA 6. Obstetrics and Gynecology, Thomas Jefferson University, Philadelphia, USA 7. Division of Infectious Diseases, University of Miami Miller School of Medicine, Miami, USA

Corresponding author: Samuel Kareff, samuel.a.kareff@gunet.georgetown.edu

\begin{abstract}
Miami-Dade County (MDC) represents a major port of entry for people seeking asylum in the United States, and few studies have systematically evaluated the demographic characteristics of this vulnerable population. Moreover, while the burden of post-traumatic stress disorder (PTSD) and major depressive disorder (MDD) are thought to be higher in this population, the prevalence of these psychiatric conditions in our community is unknown. An analysis of demographics and psychiatric co-morbidities of the Human Rights Clinic (HRC) of Miami's 93 clients between 2010 and 2015 was conducted. The HRC cohort had the following characteristics: median age of 30 years, $52 \%$ female, $46 \%$ male, $2 \%$ transgender or intersex, and 88\% originating from Latin America and the Caribbean. The prevalence of PTSD was 67\% and MDD was 53\% in the HRC population. We conclude that the mental health burden in asylum-seekers in MDC is alarmingly high and that healthcare providers should remain keenly attentive to the unique needs of this population.
\end{abstract}

Received 06/01/2020

Review began 06/08/2020 Review ended 06/23/2020 Published 07/01/2020

() Copyright 2020

Kareff et al. This is an open access article distributed under the terms of the Creative Commons Attribution License CC-BY 4.0., which permits unrestricted use, distribution, and reproduction in any medium, provided the original author and source are credited.
Categories: Psychiatry, Public Health, Epidemiology/Public Health

Keywords: asylum-seekers, refugee health, major depressive disorder, post-traumatic stress disorder

\section{Introduction}

\section{Objectives}

1) To illustrate key epidemiologic data of the Human Rights Clinic (HRC) of Miami asylum-seeking population.

2) To compare the demographics of the HRC cohort with those of Miami-Dade County (MDC).

3) To quantify the prevalence of post-traumatic stress disorder (PTSD) and major depressive disorder (MDD) through validated screening tools and compare to similar populations locally, nationally, and globally.

\section{Background}

Every year, tens of thousands of individuals arrive to the United States seeking various forms of asylum from torture and other forms of maltreatment suffered in their home countries [1]. MDC represents a major port of entry for asylum-seekers, especially those originating from Latin America and the Caribbean. While rates of PTSD and MDD are higher in populations exposed to trauma such as asylum-seekers, it is not known what the prevalence of these psychiatric conditions is among asylum-seekers residing in MDC [2-4]. Although there have been previous attempts at characterizing the medical status of asylum-seekers in MDC, little is known about the specific populations that are most likely to settle in MDC [5]. Moreover, it is difficult to project their individual needs or the impact to the local healthcare system without a demographic understanding of this population.

\section{Purpose}

The HRC, established in 2010, is an independent organization of medical students, residents, and attending physicians who complete medical and/or psychiatric examinations free of charge for individuals seeking asylum and other forms of immigration relief in South Florida. The healthcare provider's systematic documentation of evidence of torture and/or human rights abuses, either physical or psychological, is then incorporated into a legal affidavit that becomes part of an applicant's official application for asylum. This affidavit can play a crucial role in the subsequent legal decisions made about a case. It has been demonstrated previously that with the assistance of corroborating physicians, applicants who provide courts 
with medical affidavits are granted asylum at rates of up to $89 \%$, more than double the national asylum approval rate of $37.5 \%$ and higher than the average asylum approval rate in MDC which has been estimated as low as 15.6\% [6-7]. As of December 2015, HRC had evaluated 93 clients requesting legal affidavits to accompany asylum applications or other immigration proceedings petitioning legal protection within the United States. Thus, the main purpose of this study is to provide a descriptive analysis of the population served by HRC with an emphasis on the mental health needs unique to this population.

\section{Materials And Methods \\ Participants}

The HRC receives evaluation requests from a variety of community partners, including national organizations and private law firms, in the MDC metropolitan area. This analysis included all clients who received an evaluation from HRC between May 2010 and December 2015. Clients of the clinic are generally adults aged 18 and over who have requested the services of the clinic through their legal representation. Clients or their legal guardians provide informed, written consent to participate in clinic activities. The HRC clients are interviewed in physician or legal offices, free clinics, or immigration detention centers.

\section{Data collection}

The HRC student coordinators maintain a password-protected, secured, and de-identified database including information collected prior to and during evaluations. Such information includes basic demographics, type of immigration case, referral source, reasons for seeking asylum, history of torture/human rights abuses reported, and case outcomes.

\section{Measures and analyses}

A retrospective, descriptive analysis of the HRC database was performed. Demographics are reported as percentages, frequency distributions, and central tendencies. Prevalence of PTSD and MDD were operationalized by positive screening results on the PLC-C Civilian Screening Tool, a validated screening instrument for PTSD from the United States Veterans Administration, and the PHQ-9 or HAM-D, validated screening tools for MDD that utilize DSM-IV depression diagnostic criteria [8-11]. Stata (version 12.0, StataCorp, College Station, TX) was used for all analyses.

\section{Ethics approval}

The Office of the Human Research Protection Program of the University of Miami Miller School of Medicine considered this secondary data analysis of previously collected, de-identified data exempt from additional review.

\section{Results}

Some key demographic data points regarding the HRC cohort, along with parameters from MDC at large, are presented in Table 1 [12]. Some 93 clients were evaluated between 2010 and 2015. Specifically, the cohort's average age was 30 years. The proportion of women was $51 \%(n=47)$, with a remaining $47 \%$ male $(n=44)$ and $2 \%$ transgender or intersex $(n=2)$. Some $88 \%(n=82)$ of clients were from Latin American or Caribbean countries, with $47 \%(n=44)$ nationals of Central American countries. 


\section{Cureus}

\begin{tabular}{|c|c|c|}
\hline Parameter & HRC cohort & MDC \\
\hline $\mathrm{N}$ & 93 & $2,662,874$ \\
\hline Median Age, Years (SD) & 30 (13.4) & 39.3 (N/A) \\
\hline \multicolumn{3}{|l|}{ Gender (\%) } \\
\hline Female & 50.5 & 51.4 \\
\hline Male & 47.3 & 48.6 \\
\hline Trans/Intersex & 2.2 & N/A \\
\hline \multicolumn{3}{|l|}{ Preferred Language (\%) } \\
\hline English & 14 & 27.7 \\
\hline Other than English & 86 & 72.3 \\
\hline Spanish & 56 & N/A \\
\hline Haitian Creole & 26 & N/A \\
\hline Other & 4 & N/A \\
\hline \multicolumn{3}{|l|}{ Region of Birth of Foreign Born (\%) } \\
\hline Latin America and the Caribbean & 88.2 & 92.7 \\
\hline Not Latin American and the Caribbean & 11.8 & 7.3 \\
\hline Asia & 6.5 & 2.8 \\
\hline Europe & 3.2 & 3.5 \\
\hline Africa & 2.2 & 1 \\
\hline
\end{tabular}

TABLE 1: Key demographic characteristics of 93 clients served by the HRC of Miami compared to those of MDC.

HRC, Human Rights Clinic; MDC, Miami-Dade County

Some $67 \%(n=62)$ and $53 \%(n=49)$ of the HRC cohort screened positive for PTSD and MDD, respectively. Furthermore, $82 \%(n=76)$ reported history of torture and/or human rights abuses including physical, psychological, sexual, or multiple forms of trauma. The most common forms of torture were beatings and/or whippings $(67 \%, \mathrm{n}=62)$ and cutting/stabbing with sharp instruments $(15 \%, \mathrm{n}=14)$. Other forms of torture reported by HRC clients included, but were not limited to, heat and chemical burns, electric shock, suffocation and/or drowning, suspension, and witnessed torture and killings. Some 20\% ( $\mathrm{n}=19)$ of clients were fleeing gang or drug trafficking-related violence, including $50 \%(n=12)$ of unaccompanied minors.

Rates of intimate partner violence were $38 \%(n=18)$ among women and $100 \%(n=2)$ among transgender clients. Additionally, $66 \%(n=31)$ of women and $50 \%(n=1)$ of transgender clients reported sexual violence. Rates of reported adverse childhood experiences such as domestic or sexual abuse were $33 \%(n=31)$ among all clients, and 71\% (n=17) among unaccompanied minors.

\section{Discussion}

Demographically, the HRC cohort mirrored the MDC population at large in terms of median age (30 and 39.9, respectively), gender (51 and 51.4\% female, respectively), and region of origin ( 88.2 and $92.7 \%$ from Latin American and the Caribbean, respectively). This observation could be explained by familial, cultural, economic, and political ties between the local setting and asylum-seekers' native countries. Such a "pull” represents one means by which these populations can cope with the stress of acculturating to a new milieu [13]. Notably, the most common countries of origin of the HRC cohort differed drastically from the general population of asylum seekers in the United States with more Asian and African countries 


\section{Cureus}

represented nationally (see Table 2) [14].

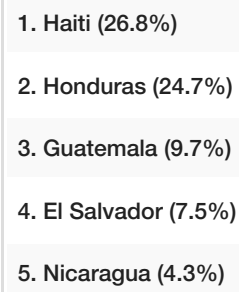

\section{United States (2015) (total \% originating)}
1. Myanmar (Burma) (26.3\%)
2. Iraq $(18.1 \%)$
3. Somalia $(12.7 \%)$
4. Democratic Republic of Congo (11.3\%)
5. Bhutan (8.3\%)

TABLE 2: The five most common countries of origin for HRC and United States asylum-seekers. HRC, Human Rights Clinic

\section{New contributions to the literature}

Conversely, the HRC cohort displayed a high prevalence of PTSD (67\%) and MDD (53\%). These findings are consistent with other studies of asylum-seekers and refugees around the world. For example, Bosnian refugees who resettled in Austria and Australia were also found to have higher prevalences of PTSD, depressive, and anxiety symptoms upon arrival [15]. Furthermore, 36.1\% of various African refugees in Hong Kong and $38.3 \%$ of Somali refugees in Ethiopia were found to screen positive for depressive symptoms [1617]. Moreover, the HRC cohort's prevalences of these mental health conditions are much higher than estimates for the general South Florida population (8.4\% PTSD and 11.6\% MDD) or United States (3.5\% PTSD and 6.7\% MDD) populations (see Figure 1) [18-19].

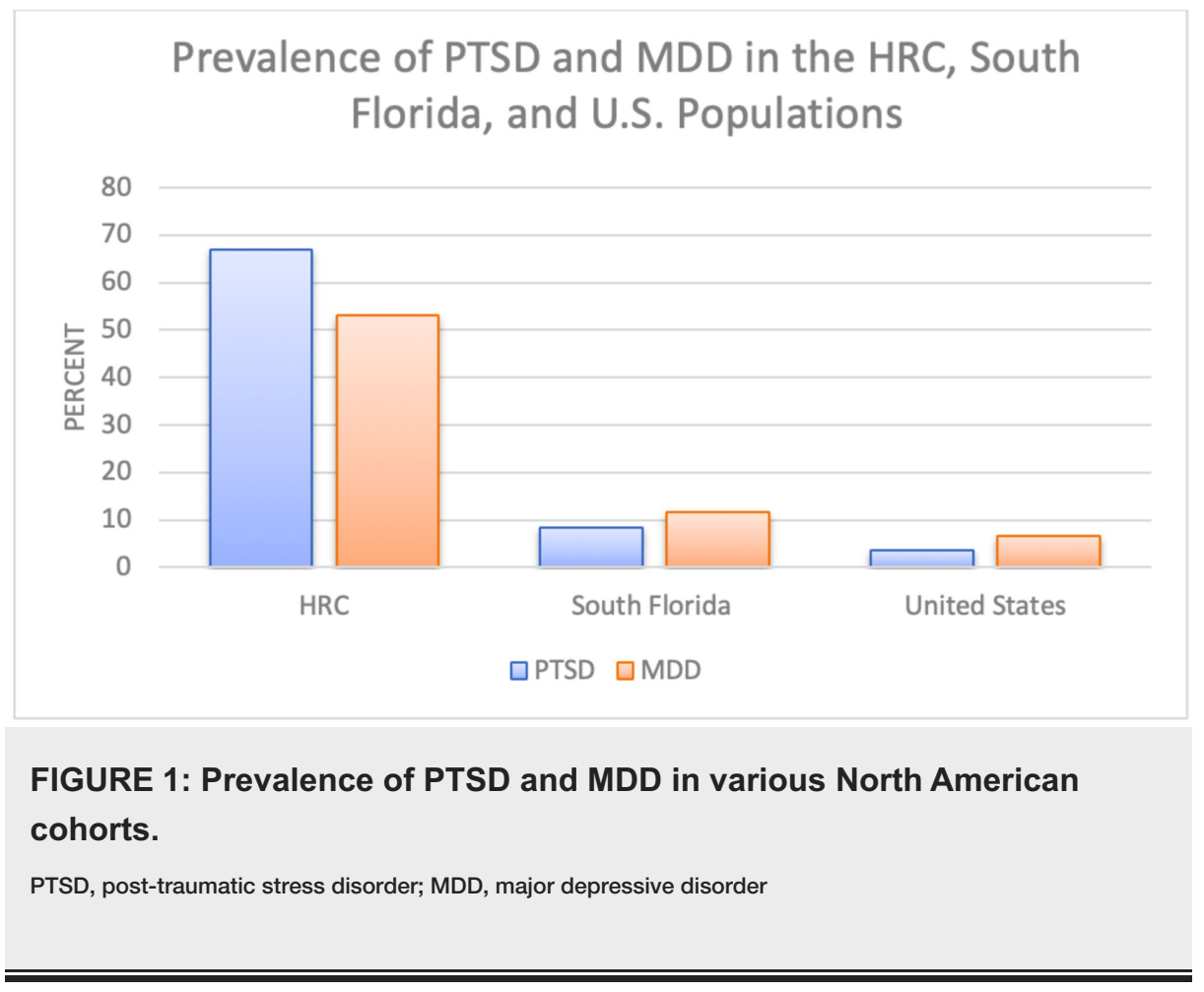

Notably, $82 \%$ of the HRC cohort reported episodes of torture and/or human rights abuses; prevalence estimates of torture history vary from $6.6 \%$ at an urban primary care clinic to $11.5 \%$ in an urban emergency department cohort, and often go unreported [20-21]. Furthermore, the asylum-seekers' legal affidavits reveal a wide variety of types of abuse suffered including persecution of marginalized political sects in Ethiopia, gang violence in Honduras and El Salvador, and sexual assault in Haiti and the Bahamas.

\section{Limitations}

To the authors' knowledge, these estimates provide the first demographic and medical evidence regarding 
the unique cohort of asylum-seekers who settle in MDC. However, a significant limitation to our findings is the lack of validation of the PLC-C, PHQ-9, and HAM-D screening tools in our specific study population, as these instruments have only been previously validated for primary care settings. Another argument is that the data we have presented herein might resemble a convenience sample due to their physical location during interview; detained individuals constitute a significant minority of our study population (14\%, n=13).

An additional limitation of our data is its focus on the psychiatric comorbidities exhibited by the HRC cohort upon the time of medical/psychiatric evaluation. Further research is needed to clarify acute medical conditions also experienced by this vulnerable population, including injuries related to instances of trauma and torture. Screening for other chronic medical conditions, including overweight, hypertension, diabetes mellitus, and chronic pain for which this population may be at greater risk, would also be of benefit for elucidating this population's medical burden.

\section{Implications for public health practice}

The data discussed in this analysis can have important implications for local officials, public health officers, and healthcare providers. First and foremost, these findings highlight that additional resources should be dedicated to assist these clients with their large burden of psychiatric comorbidities. Currently, the Florida Department of Health in MDC operates a Refugee Health Assessment Program (RHAP) in which a "mental health evaluation and referral” process is available to refugees, parolees, and asylum-seekers who lawfully enter into the United States [22]. It would benefit the HRC cohort as well as larger populations, including Cuban and Haitian entrants, for the RHAP to develop a more robust mental health arm capable of reaching populations in need. Secondly, healthcare providers practicing in MDC, as well as other major ports of entry, should have a greater knowledge and understanding of the unique mental health needs of asylum-seekers settling within the United States, and should screen these patients for histories of trauma and torture. This is essential given that evidence suggests that stigma and discrimination targeting these populations can lead to a poorer quality of care [23].

\section{Conclusions}

Asylum-seekers in MDC mirror the demographics of the county at large but appear to have a much larger burden of psychiatric co-morbidities including PTSD and MDD. Moreover, the majority of these individuals has faced episodes of torture and/or human rights abuses in their countries of origin. These results suggest that local public health authorities and healthcare providers design tailored outreach programming to target this vulnerable population and ensure access to needed services.

\section{Additional Information \\ Disclosures}

Human subjects: Consent was obtained by all participants in this study. University of Miami Miller School of Medicine issued approval 20140865. The IRB approved this study from 30th June 2015. Animal subjects: All authors have confirmed that this study did not involve animal subjects or tissue. Conflicts of interest: In compliance with the ICMJE uniform disclosure form, all authors declare the following: Payment/services info: All authors have declared that no financial support was received from any organization for the submitted work. Financial relationships: All authors have declared that they have no financial relationships at present or within the previous three years with any organizations that might have an interest in the submitted work. Other relationships: All authors have declared that there are no other relationships or activities that could appear to have influenced the submitted work.

\section{References}

1. U.S. Department of Justice, Executive Office for Immigration Review. Asylum Statistics FY 2010-2014 . (2015). Accessed: June 1, 2017: https://www.justice.gov/sites/default/files/eoir/pages/attachments/2015/03/16/fy2010-fy2014-asylumstatistics-by-nati....

2. Crumlish N, O’Rourke K: A systematic review of treatments for post-traumatic stress disorder among refugees and asylum-seekers. J Nervous Mental Dis. 2010, 198:237-253. 10.1097/NMD.0b013e3181d61258

3. Fazel M, Hyman I, Noh S: Determinants of depression among Ethiopian immigrants and refugees of Toronto. J Nervous Mental Dis. 2004, 192:362-372.

4. Piwowarczky L: Asylum seekers seeking mental health services in the United States: clinical and legal implications. J Nervous Mental Dis. 2007, 195:715-722. 10.1097/NMD.0b013e318142ca0b

5. Entzel PP, Fleming LH, Trepka MJ, Squicciarini D: The health status of newly arrived refugee children in Miami-Dade County, Florida. Am J Public Health. 2003, 93:286-288. 10.2105/ajph.93.2.286

6. Lustig SL, Kureshi S, Delucchi KL, Iacopino V, Morse SC: Asylum grant rates following medical evaluations of maltreatment among political asylum applicants in the United States. J Immigrant Minority Health Center of Minority Public Health. 2007, 10:7-15. 10.1007/s10903-007-9056-8

7. Asylum Outcome Increasingly Depends on Judge Assigned. (2009). Accessed: June 1, 2017: http://trac.syr.edu/immigration/reports/447/.

8. PLC-C Civilian Screening Tool for PTSD. United States Veterans Administration . (2017). Accessed: June 1, 2017: http://www.mirecc.va.gov/docs/visn6/3_PTSD_CheckList_and_Scoring.pdf. 
9. The Patient Health Questionnaire (PHQ-9). Center for Quality Assessment and Improvement in Mental Health. (2017). Accessed: June 1, 2017: http://www.cqaimh.org/pdf/tool_phq9.pdf.

10. Williams JBW: A structured interview guide for the Hamilton Depression Rating Scale . Arch Gen Psychol. 1998, 45:742-747. 10.1001/archpsyc.1988.01800320058007

11. DSM-IV Sourcebook. American Psychiatric Association, Washington, DC; 1994.

12. Miami-Dade County Profiles. 2014 American Community Survey . (2014). Accessed: June 1, 2017: http:// https://data.census.gov/cedsci/table?d=ACS\%205-

Year\%20Estimates\%20Data\%20Profiles \&table=DP05\&tid=ACSDP5Y2014.....

13. Porter M, Haslam N: Predisplacement and postdisplacement factors associated with mental health of refugees and internally displaced persons: a meta-analysis. JAMA. 2005, 294:602-612. 10.1001/jama.294.5.602

14. Refugees and Asylees in the United States. Migration Policy Institute . (2017). Accessed: June 1, 2017: http://www.migrationpolicy.org/article/refugees-and-asylees-united-states\#Refugee_Arrivals .

15. Kartal D, Kiropoulos L: Effects of acculturative stress on PTSD, depressive, and anxiety symptoms among refugees resettled in Australia and Austria. Eur J Psychotraumatol. 2016, 12:28711. 10.3402/ejpt.v7.28711

16. Wong WCM, Cheung S, Miu HYH, Chen J, Looper KA, Holroyd E: Mental health of African asylum-seekers and refugees in Hong Kong: using the social determinants of health framework. BMC Public Health. 2017, 17:153. 10.1186/s12889-016-3953-5

17. Feyera F, Mihretie G, Bedaso A, Gedle D, Kumera G: Prevalence of depression and associated factors among Somali refugee at Melkadida camp, southeast Ethiopia: a cross-sectional study. BMC Psychiatry. 2015, 15:171. 10.1186/s12888-015-0539-1

18. Turner RJ, Gil AG: Psychiatric and substance use disorders in South Florida . Arch Gen Psychol. 2002, 59:4350.

19. Epidemiology of PTSD. U.S. Department of Veterans Affairs . (2017). Accessed: June 1, 2017: http:// https://www.ptsd.va.gov/understand/common/common_adults.asp.

20. Eisenman DP, Keller AS, Kim G: Survivors of torture in general medical setting: how often have patients been tortured, and how often is it missed?. Western J Med. 2000, 172:301-304.

21. Hexom B, Fernando D, Manini AF: Survivors of torture: prevalence in an urban emergency department . Acad Emergency Med. 2012, 19:1158-1165. 10.1111/j.1553-2712.2012.01449.x

22. Refugee Health Assessment Program. Florida Department of Health in Miami-Dade County . (2017). Accessed: June 1, 2017: http://miamidade.floridahealth.gov/programs-and-services/clinical-and-nutritionservices/refugee-health-assessment-pr....

23. Racism as a Determinant of Immigrant Health: A Report for the Strategic Initiatives and Innovations Directorate, Public Health Agency of Canada. (2009). Accessed: June 1, 2017: http:// https://webcache.googleusercontent.com/search? q=cache:v1RceWL5Js4J:https://www.metropolis.net/pdfs/racism_pol.... 